DOT/FAA/AM-11/13

Office of Aerospace Medicine

Washington, DC 20591

\title{
Drugs and Alcohol in Civil Aviation Accident Pilot Fatalities From 2004-2008
}

Dennis V. Canfield

Kurt M. Dubowski

Arvind K. Chaturvedi

James E. Whinnery

Civil Aerospace Medical Institute Federal Aviation Administration Oklahoma City, OK 73125

September 2011

Final Report 


\section{NOTICE}

This document is disseminated under the sponsorship of the U.S. Department of Transportation in the interest of information exchange. The United States Government assumes no liability for the contents thereof.

This publication and all Office of Aerospace Medicine technical reports are available in full-text from the Civil Aerospace Medical Institute's publications Web site: www.faa.gov/library/reports/medical/oamtechreports 
Technical Report Documentation Page

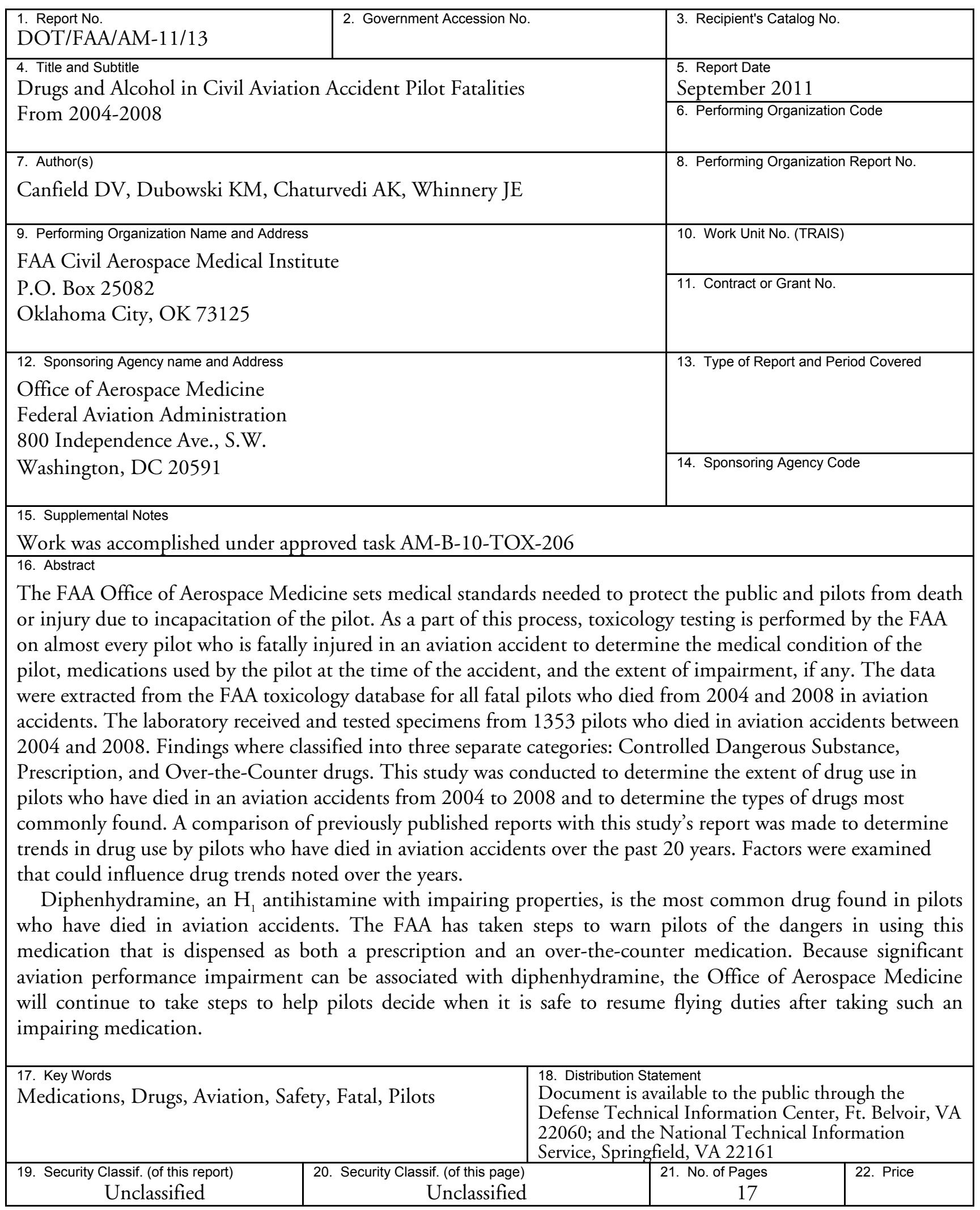

Form DOT F 1700.7 (8-72)

Reproduction of completed page authorized 



\section{CONTENTS}

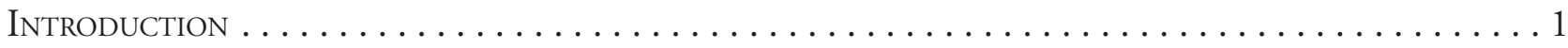

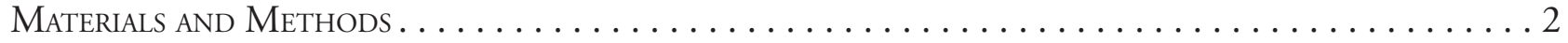

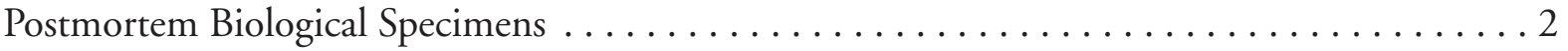

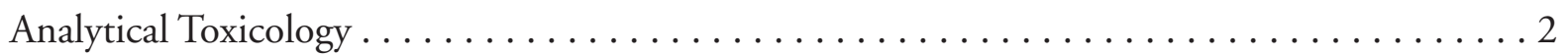

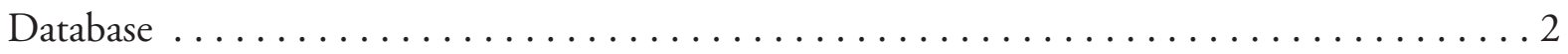

Drug Classification (or Grouping) and Pilot Fatality Numbers. . . . . . . . . . . 3

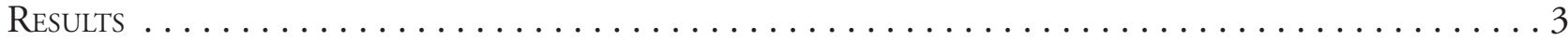

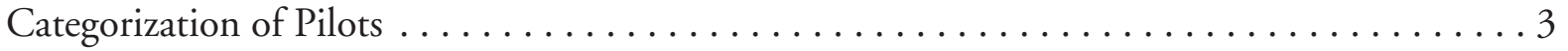

Fatal Pilots Positive for Drugs/Medications $\ldots \ldots \ldots \ldots \ldots \ldots \ldots \ldots \ldots \ldots$

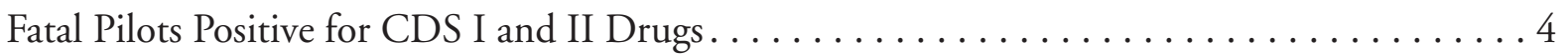

Positive Fatal Pilots Taking CDS Class III - V Drugs $\ldots \ldots \ldots \ldots \ldots \ldots \ldots \ldots \ldots \ldots$

Positive Fatal Pilots Taking Prescription $(\mathrm{Rx})$ Medications $\ldots \ldots \ldots \ldots \ldots \ldots \ldots \ldots$

Positive Fatal Pilots Taking Over-the-Counter (OTC) Medications . . . . . . . . . . . . 5

Fatal Pilots With Positive Alcohol (Ethanol) at or Above $0.04 \% \ldots \ldots \ldots \ldots \ldots \ldots$

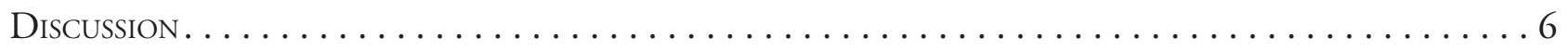

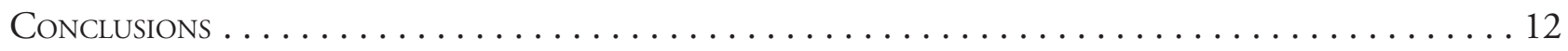

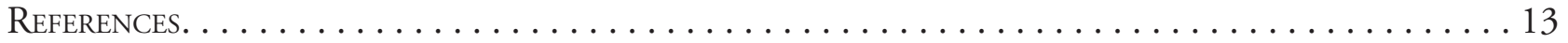





\section{Drugs and Alcohol Found in Civil Aviation Accident Pilot Fatalities From 2004-2008}

\section{INTRODUCTION}

The Federal Aviation Administration (FAA) Office of Aerospace Medicine provides pilot medical standards to protect the public's interests and prevent death and injury of pilots, crew, and passengers. Pilots are required by FAA regulations to report all medications used and medical conditions to the FAA Office of Aerospace Medicine for review and consideration as to the overall suitability of the pilot for flight activities. In the event of an aircraft accident, an integral part of the FAA's comprehensive safety mission includes conducting a forensic toxicology analysis of every pilot fatality. Following a fatal aviation accident, specimens from deceased pilots are collected by local pathologists and sent to the Civil Aerospace Medical Institute's (CAMI's) Bioaeronautical Sciences Research Laboratory for toxicological analysis. The analysis determines the drugs present in postmortem tissues and fluids of fatally injured pilots that may have been the cause or a factor in the aircraft mishap.

The toxicological results are utilized for individual aircraft accident investigation to determine the cause(s) of a particular accident and to gather data for research purposes. The toxicological results for each accident also provides essential information for medical certification specialists in terms of ensuring that the pilot was in compliance with and had been appropriately medically certified to fly. In addition to the importance for individual aircraft accident analysis, the toxicological results are continuously reviewed to understand trends associated with medications or drug use that might become evident such that proactive and preventive measures can be initiated to ensure continuous aviation safety improvement.

Trend analysis may provide evidence to support proactive changes in airman medical certification activities, as well as proactive pilot education programs that alert pilots of the increasing risks associated with medications. All of these activities are integrated as a part of the continuous FAA aviation safety management program. We have previously instituted a program that formally reviews the trends associated with drugs and alcohol found in toxicological analysis over 5-year time periods. It is important to realize that the trend analysis is complicated by an ever-changing process in drug availability, laboratory modifications, drug incident rates, and other factors. With the above goals and limitations in mind, we present the results of the drug positive findings for three previous 5-year studies defining the drugs found in pilot fatalities by the forensic toxicology program at CAMI.

This 5-year study is a continuation of the previous three 5-year studies of drugs found in pilot fatalities (1-3). The 1999-2003 study, consisting of 1587 pilots, showed controlled dangerous substance (CDS) I-II drugs in 113 (7\%) pilots, CDS III-V in 42 (3\%) pilots, prescription medications were present in $315(20 \%)$ pilots, nonprescription drugs in $259(16 \%)$ pilots, and ethanol in 101 (6\%) pilots (3). The 1994-1998 study, consisting of 1683 pilots, showed CDS I-II drugs in 89 (5\%) pilots, CDS III-V in 49 (3\%) pilots, prescription medications were present in $240(14 \%)$ pilots, nonprescription drugs in 301 (18\%) pilots, and ethanol in 124 (7\%) pilots (2). The 1989-1993 study (1845 pilots) showed CDS I-II drugs in 74 (4\%) pilots, CDS III-V in $28(2 \%)$ pilots, prescription medications were present in $110(6 \%)$ pilots, nonprescription drugs in $207(11 \%)$ pilots, and ethanol in 146 (8\%) pilots (1). These early studies and others (4-9) have been conducted on the prevalence of drugs found in pilots. However, they do not necessarily take into consideration all of the factors that might have influenced the number of drugs detected in those fatalities.

Many of the factors shown in Table 1 can and do affect drug trends reported in the literature. Therefore, changes in drug trends reported in other studies may not reflect an increase or decrease in accident risk or drug use. The changes found could be caused by the factors listed in Table 1. The prevalence of drugs in a population is influenced by laws, analytical methods, procedures, and population differences. In the present study these factors were evaluated because all analyses were performed and all data maintained in-house at CAMI. The drug use reported in other studies often came from a diverse group of laboratories as is the case for the Drug Abuse Warning Network (DAWN) information system(10). The data reported in the present study were reviewed to determine what, if any, affect these factors might have on the frequency rates of drugs or their presence reported in this study. 
Table 1. Factors affecting the appearance and frequency of drug test findings.

\begin{tabular}{|c|c|c|}
\hline I & Regulatory/Manufacturing & Description \\
\hline & 1 & Date Food and Drug Administration (FDA) approved medication \\
\hline & 2 & Date of withdrawal of FDA approval of medication \\
\hline & 3 & Changes in prescription legal status \\
\hline & 4 & Change of medication from brand name to generic medication \\
\hline \multirow[t]{4}{*}{ II } & Laboratory Methodology & Description \\
\hline & 1 & Changes in analytical methods and target analytes \\
\hline & 2 & Changes in analytical reporting cutoff levels for specific drugs \\
\hline & 3 & Changes in analytical instrumentation \\
\hline \multirow[t]{5}{*}{ III } & Population Dynamics & Description \\
\hline & 1 & Prescription frequency rates \\
\hline & 2 & Gender distribution \\
\hline & 3 & Age distribution \\
\hline & 4 & Pilot population and certification status \\
\hline \multirow[t]{2}{*}{ IV } & Administrative & Description \\
\hline & 1 & Availability of medical history \\
\hline
\end{tabular}

\section{MATERIALS AND METHODS}

\section{Postmortem Biological Specimens}

By law, the autopsied biological samples (blood, urine, liver, kidney, vitreous fluid, and other body specimens) collected from pilot fatalities in civil aircraft accidents were submitted to CAMI for toxicological testing. Not all of the pilots involved in these accidents were necessarily certified by the FAA to fly an aircraft. The specimens submitted for analysis were coordinated through the FAA's Office of Accident Investigation and the National Transportation Safety Board (NTSB). The collected samples are submitted in custom-built FAA evidence containers (TOX-BOX) that provide all necessary instructions and materials for standardized toxicological collection and processing.

\section{Analytical Toxicology}

Postmortem specimens were collected from pilot fatalities during 2004-2008. The biological specimens received for testing are routinely analyzed for the presence of combustion gases (carbon monoxide and hydrogen cyanide); a wide range of illicit, prescription, and nonprescription drugs; plus alcohol/volatiles. Specimens are screened, confirmed, and quantitated for the analytes mentioned above. All specimens are analyzed according to established standard procedures approved for use by the CAMI Laboratory (11). The methods used included gas chromatography, liquid chromatography, ultraviolet/visible spectrophotometry, immunoassay, gas chromatography/mass spectrometry (GC/MS), and liquid chromatography/mass spectrometry (LC/MS). Ethanol analysis is performed by headspace gas chromatography and radioactive energy attenuation methods. Analytical procedures used are dependent upon their sensitivity and specificity, the nature of analytes, and the availability of sample types and amounts. An analyte might not necessarily be detected or even analyzed in a particular case because the specimen is unsuitable for analysis.

\section{Database}

All toxicology results from civil aircraft accident fatalities are stored electronically in a database maintained at CAMI. This database was examined for the presence of controlled dangerous substances, prescription $(\mathrm{Rx})$, nonprescription (OTC) drugs, and ethanol for this study. The database search also entailed the numbers of all aviation accidents and pilot fatalities, including the airman flying category and medical certificate class of those pilots and the flight categories of the associated accidents. Some individuals flying the plane who did not have a pilot and/or medical certificate were also part of the study. In the present study, fatalities consist of only pilots in command-copilots are not included. Caffeine and nicotine were not incorporated into the list of drugs found in the pilot fatalities. Ethanol is reported in only those cases wherein ethanol concentrations were $\geq 0.04 \%$, as the FAA regulations forbid the operation of an aircraft by a pilot with a blood ethanol concentration $\geq 0.04 \%$ (40 mg.dL-1). 
Drug Classification (or Grouping) and Pilot Fatality Numbers

Controlled dangerous substances were grouped according to the classification given by the U.S. Drug Enforcement Administration (DEA) for the pure compound. Drugs found in the fatalities were classified based upon their mere presence, even though some of the drugs could be classified differently based on the formulation. In fatalities wherein multiple drugs and ethanol were found, such fatalities were counted more than once-that is, for each drug under its respective category-and for ethanol.

\section{RESULTS}

\section{Categorization of Pilots}

As shown in Table 2, the FAA estimates of the total number of pilots (12) and the type of certificates held from 2004-2008 were utilized in defining the total average number of pilots and the number of pilots in various categories.

The laboratory received and tested specimens from 1353 pilots who had died in aviation accidents between 2004 and 2008 (Table 3). Most were males (97\%), with only 38 female pilots (3\%). The median age bracket of

Table 2. Average number of pilots and certificates issued over the 5-year period (2004-2008) compared with fatal pilots (pilot fatalities).

\begin{tabular}{|c|c|c|c|c|c|c|c|c|c|c|}
\hline Category & $\begin{array}{c}\text { Average } \\
\text { \# Pilots }\end{array}$ & $\%$ & Age & $\begin{array}{c}\text { Average } \\
\text { \# Women }\end{array}$ & $\%$ & $\begin{array}{l}\text { Fatal } \\
\text { Pilots }\end{array}$ & $\%$ & $\begin{array}{c}\text { Fatal } \\
\text { Pilot Age }\end{array}$ & $\begin{array}{c}\text { Fatal } \\
\text { Woman }\end{array}$ & $\%$ \\
\hline Student & 85,063 & 15 & 34 & 9,580 & 11.3 & 51 & 4 & 46 & 3 & 6 \\
\hline Recreational (only) & 260 & 0 & 51 & 19 & 7.3 & 0 & 0 & NA & 0 & 0 \\
\hline Sport (only) & 1,432 & 0 & 53 & 44 & 3.1 & 6 & 0 & 66 & 0 & 0 \\
\hline Private & 223,508 & 39 & 47 & 14,475 & 6.5 & 641 & 49 & 55 & 18 & 3 \\
\hline Commercial & 120,138 & 21 & 46 & 7,431 & 6.2 & 397 & 30 & 50 & 11 & 3 \\
\hline Airline Transport & 143,376 & 25 & 46 & 5,199 & 3.6 & 208 & 16 & 54 & 6 & 3 \\
\hline Total & 573,776 & 100 & 45 & 36,747 & 6.4 & $1303^{*}$ & 100 & 53 & 38 & 3 \\
\hline
\end{tabular}

*50 fatal individuals were not designated in any category listed in this table.

Table 3. All pilots tested in this study.

\begin{tabular}{|c|c|c|c|c|}
\hline & \multicolumn{4}{|l|}{ Totals Fatal Pilots } \\
Tested & \multicolumn{3}{l|}{$\mathbf{1 3 5 3}$} \\
\hline Group & Class & Level & Part & Gender \\
\hline $\mathbf{0 - 2 0}$ & $\mathbf{1}$ & $\mathbf{A}$ & $\mathbf{1 2 1}$ & $\mathbf{M}$ \\
15 & 181 & 208 & 5 & 1315 \\
\hline $\mathbf{2 1 - 3 0}$ & $\mathbf{2}$ & $\mathbf{C}$ & $\mathbf{1 3 5}$ & $\mathbf{F}$ \\
105 & 427 & 397 & 63 & 38 \\
\hline $\mathbf{3 1 - 4 0}$ & $\mathbf{3}$ & $\mathbf{P}$ & $\mathbf{9 1}$ & Unk \\
142 & 672 & 641 & 1203 & 0 \\
\hline $\mathbf{4 1 - 5 0}$ & Other & $\mathbf{S}$ & $\mathbf{1 3 7}$ & \\
$\mathbf{2 9 2}$ & 73 & 51 & 38 & \\
\hline & & & Public & \\
$\mathbf{5 1 - 6 0}$ & & $\mathbf{T}$ & Use & \\
382 & & 6 & 16 & \\
\hline $\mathbf{6 1 - 7 0}$ & & $\mathbf{Y}$ & $\mathbf{1 3 3}$ & \\
273 & & 10 & 6 & \\
\hline$>\mathbf{7 0}$ & & Unk & Unk & \\
141 & & 40 & 22 & \\
\hline Unk & & & & \\
\hline 3 & & & & \\
\hline $\mathbf{1 3 5 3}$ & $\mathbf{1 3 5 3}$ & $\mathbf{1 3 5 3}$ & $\mathbf{1 3 5 3}$ & $\mathbf{1 3 5 3}$ \\
\hline
\end{tabular}


the pilots was 51-60 years old. The majority (44\%) of the pilots held a third-class medical certificate, and most (48\%) were designated as private pilots. Only five pilots were flying Title 14 of the Code of Federal Regulations (CFR) Part 121 (air transport) at the time of the accident. The vast majority of the fatal pilots, 1203 (89\%), were flying CFR Part 91 (general aviation). A total of 63 pilots (5\%) were flying CFR Part 135 (commuter flights).

\section{Fatal Pilots Positive for Drugs/ \\ Medications}

Drugs/medications were found in 570 pilots from 1353 (42\%) total fatal pilots tested (Table 4). Of the 570 pilots with positive drug/medication findings, 550 were males (96\%) and 20 females (4\%). Two Part 121 pilots were found to be taking medications; one had diphenhydramine (Benadryl ${ }^{\circledR}$ ) in his system, and another was found to have acetaminophen (Tylenol $\left.{ }^{\circledR}\right)$ in his system. Most of the pilots with positive drug results, 511 (90\%), were flying under CFR Part 91.

Table 4. Total fatal pilots using drugs.

\begin{tabular}{|c|c|c|c|}
\hline \multicolumn{4}{|c|}{ Pilots Using Drugs } \\
\hline Age & Class & Level & Part \\
\hline $\mathbf{0 - 2 0}$ & $\mathbf{1}$ & $\mathbf{A}$ & $\mathbf{1 2 1}$ \\
1 & 58 & 84 & 2 \\
\hline $\mathbf{2 1 - 3 0}$ & $\mathbf{2}$ & $\mathbf{C}$ & $\mathbf{1 3 5}$ \\
32 & 159 & 151 & 18 \\
\hline $\mathbf{3 1 - 4 0}$ & $\mathbf{3}$ & $\mathbf{P}$ & $\mathbf{9 1}$ \\
43 & 306 & 284 & 511 \\
\hline $\mathbf{4 1 - 5 0}$ & $\mathbf{4}$ & $\mathbf{S}$ & $\mathbf{1 3 7}$ \\
99 & 4 & 20 & 20 \\
\hline $\mathbf{5 1 - 6 0}$ & $\mathbf{9}$ & $\mathbf{T}$ & Public Use \\
163 & 7 & 4 & 6 \\
\hline $\mathbf{6 1 - 7 0}$ & Unk & Y & $\mathbf{1 3 3}$ \\
144 & 36 & 5 & 2 \\
\hline$>\mathbf{7 0}$ & & Unk & Unk \\
86 & & 22 & 11 \\
\hline Unk & & & \\
2 & & & $\mathbf{5 7 0}$ \\
\hline $\mathbf{5 7 0}$ & $\mathbf{5 7 0}$ & $\mathbf{5 7 0}$ & \\
\hline
\end{tabular}

\section{Fatal Pilots Positive for CDS I and II Drugs}

As noted in Table 5, a total of 79 (6\%) of 1353 pilots were found to have CDS (CI-CII) drugs in their system. Most, 70 (89\%), of the CI-CII drug positive pilots were flying CFR Part 91. No CFR Part 121 pilots were found to have CI-CII drugs in their system. We did find three pilots flying commuter flights who had CI-CII drugs in their system. Four agricultural pilots (5\%) were found to be taking CI-CII drugs. Of 208 fatal pilots tested with an air transport pilot rating, only $8(4 \%)$ were found to be taking CDS I-II drugs. None of these pilots was flying CFR Part 121 at the time of the crash. Of these eight pilots, six were taking Department of Transportation (DOT) illegal drugs. Only three of the six airline transport rated pilots were flying Part 135; cocaine (a DOT illegal Drug) was found in two $(<1 \%)$ of the pilots, and one was positive for meperidine (Demerol $\left.{ }^{\circledR}\right)$. There were 397 pilots holding a commercial pilot rating, and 24 of these fatal pilots $(6 \%)$ tested positive for CDS I-II drugs. Forty private pilots $(6 \%)$ were positive for CDS I-II drugs of 641 private pilots tested. No pilot rating was available for four (10\%) of the CI-CII drug-positive cases of a total of 40 fatal undesignated pilots.

Ten (6\%) of 181 pilots with a first-class medical certificate were positive for CDS I-II drugs; not all of these pilots were rated as air transport pilots. There were 427 pilots tested with second-class medical certificate, and 21(6\%) of these pilots were found to be positive for CDS I-II drugs. This study found $42(6 \%)$ pilots with a third-class medical positive for CDS I-II drugs of 672 tested pilots.

\section{Positive Fatal Pilots Taking CDS Class III - V Drugs}

As given in Table 5, 48 (4\%) of 1353 pilots were found to be taking CDS (CIII-CV). Most, 45 (94\%), of the CIII-CV drug positive pilots were flying CFR Part 91. No pilot flying CFR Part 121 or Part 135 was found to be taking CIII-CV drugs. There was one (2\%) agricultural pilot flying CFR Part 137 found to be taking CIII-CV drugs. No information was available regarding the type of flying in two (4\%) positive cases for CIII-CV drugs.

Of 208 fatal pilots tested with an air transport pilot rating, only six pilots (3\%) were found to be taking CDS III-V drugs. None of these pilots was flying CFR Part 121 at the time of the crash. Of 397 pilots holding a commercial pilot rating, there were 17 fatal pilots (4\%) using CDS III-V drugs. Twenty-one general aviation pilots $(3 \%)$ were positive for CDS III-V of 641 private pilots tested.

There were four (2\%) of 181 pilots with a firstclass medical certificate taking CDS III-V; not all of them were rated as air transport pilots. There were 427 pilots with second-class medical certificates, and $13(3 \%)$ of these pilots were found to be taking CDS III-V drugs. This study found $28(4 \%)$ pilots with a third-class medical taking CDS III-V drugs of 672 third-class medical certificate pilots. 
Table 5. Positive fatal pilots by drug class.

\begin{tabular}{|l|c|c|c|c|c|}
\hline \multirow{2}{*}{ Type } & \multicolumn{6}{|c|}{ Drug Class } \\
\cline { 2 - 6 } & CI-CII & CIII-CV & RX & OTC & Ethanol \\
\hline Part 121 (5) & 0 & 0 & 1 & 1 & 0 \\
Part 133 (6) & 0 & 0 & 1 & 1 & 1 \\
Part 135 (63) & 3 & 0 & 11 & 9 & 1 \\
Part 137 (38) & 4 & 1 & 15 & 5 & 1 \\
Part 91 (1203) & 70 & 45 & 349 & 156 & 86 \\
Part Unk (22) & 2 & 2 & 9 & 2 & 1 \\
Public Use (16) & 0 & 0 & 4 & 1 & 2 \\
\hline Totals (1353) & $\mathbf{7 9}$ & $\mathbf{4 8}$ & $\mathbf{3 9 0}$ & $\mathbf{1 7 5}$ & $\mathbf{9 2}$ \\
\hline Airline Transport (208) & 8 & 6 & 60 & 23 & 13 \\
Commercial (397) & 24 & 17 & 98 & 50 & 22 \\
Private (641) & 40 & 21 & 196 & 84 & 50 \\
Student (51) & 3 & 3 & 11 & 9 & 3 \\
No Designation (40) & 4 & 1 & 17 & 8 & 3 \\
Sport (6) & 0 & 0 & 3 & 1 & 0 \\
Foreign (10) & 0 & 0 & 5 & 0 & 1 \\
\hline Totals (1353) & $\mathbf{7 9}$ & $\mathbf{4 8}$ & $\mathbf{3 9 0}$ & $\mathbf{1 7 5}$ & $\mathbf{9 2}$ \\
\hline Med Class 1 (181) & 10 & 4 & 34 & 21 & 12 \\
Med Class 2 (427) & 21 & 13 & 108 & 42 & 26 \\
Med Class 3 (672) & 42 & 28 & 212 & 95 & 50 \\
Med Class Other (73) & 6 & 3 & 36 & 17 & 4 \\
\hline Totals (1353) & $\mathbf{7 9}$ & $\mathbf{4 8}$ & $\mathbf{3 9 0}$ & $\mathbf{1 7 5}$ & $\mathbf{9 2}$ \\
\hline
\end{tabular}

$\tau$ - Unknown

\section{Positive Fatal Pilots Taking Prescription (Rx) Medications}

As shown in Table 5, a total of 390 (29\%) of 1353 pilots were found to be taking prescription $(\mathrm{Rx})$ medications. Most, 349 (89\%), of the Rx drug-positive pilots were flying CFR Part 91. Only one airline transport pilot flying CFR Part 121 was found to be taking an Rx medication. There were 11 (3\%) of the pilots flying CFR Part 135 taking $\mathrm{Rx}$ medications. Fifteen (4\%) agricultural pilots were found to be taking $\mathrm{Rx}$ medications. No information was available regarding the type of flying in nine (2\%) positive cases for $\mathrm{Rx}$ medications.

Of 208 fatal pilots tested with an air transport pilot rating, 60 (30\%) where found to be taking Rx medications. Only one of these pilots was flying Part 121 at the time of the crash. Of 397 pilots with a commercial pilot rating, there were 98 fatal pilots (25\%) positive for $\mathrm{Rx}$ medications. There were 196 pilots $(30 \%)$ with a private pilot rating found to be using Rx medications of 641 private pilots tested.

There were $34(19 \%)$ of 181 pilots with a first-class medical certificate taking $\mathrm{Rx}$ medications; not all of them were rated as airline transport pilots. There were 427 pilots with second-class medical certificate, and 108 (26\%) of these pilots were found to be taking $\mathrm{Rx}$ medications. This study found 212 (32\%) pilots with a third-class medical taking Rx medications of 672 third-class medical pilots.

\section{Positive Fatal Pilots Taking Over-the-Counter (OTC) Medications}

As Table 3 indicates, 175 (13\%) of 1353 pilots were found to be taking OTC medications. Most, 156 (12\%), of the OTC medications-positive pilots were flying CFR Part 91 (general aviation). Only one pilot flying CFR Part 121 was found to be taking OTC medications. There were nine (1\%) pilots flying CFR Part 135 taking OTC medications. Five $(<1 \%)$ agricultural pilots were found to be taking OTC medications. No information was available regarding the type of flying in two $(<1 \%)$ cases positive for OTC medications.

Of 208 fatal pilots tested with an air transport pilot rating, $23(11 \%)$ where found to be taking OTC medications. Only one of these pilots was flying Part 121 at the time of the crash. Of 397 pilots holding a commercial pilot rating, there were 50 fatal pilots (13\%) using OTC medications. There were 84 pilots $(13 \%)$ holding a private pilot rating found to be using OTC medications (641 private pilots were tested). 
Twenty-one (12\%) of 181 pilots with a first-class medical certificate were taking OTC medications; not all of them were necessarily rated as airline transport pilots. There were 427 pilots with second-class medical certificates, and $42(10 \%)$ were found to be taking OTC medications. This study found 95 pilots (14\%) with a third-class medical taking OTC medications of 672 third-class medical pilots.

\section{Fatal Pilots With Positive Alcohol (Ethanol) at or Above 0.04\%}

Table 5 shows that a total of $92(7 \%)$ of 1353 pilots were found to have ethanol (alcohol) present in their specimens at or above the FAA limit of $0.04 \mathrm{~g} / \mathrm{dL}$. Most, 86 (6\%), of the ethanol-positive pilots were flying CFR Part 91. No pilot flying CFR Part 121 was found to be flying in violation of FAA alcohol regulations. Only one pilot flying CFR Part 135 and one pilot flying CFR Part 137 were found to have ethanol in violation of FAA regulations. The pilot flying CFR Part 137 had a 0 serotonin urine metabolite ratio. No information was available regarding the type of flying in two cases positive for ethanol.

Of 208 fatal pilots tested with an air transport pilot rating, $13(6 \%)$ where found to have ethanol in excess of FAA regulations. None of these pilots was flying Part 121 at the time of the crash. Of 397 pilots with a commercial pilot rating, $22(6 \%)$ fatal pilots had ethanol concentrations at or above FAA regulations. Fifty private pilots (8\%) of 641 tested were found to be in violation of FAA regulations.

There were $12(7 \%)$ of 181 pilots with a first-class medical certificate in violation of FAA regulations; not all of these pilots were necessarily rated as air transport pilots. There were 427 pilots with a second-class medical certificate, and $26(6 \%)$ of these pilots were found to exceed the FAA alcohol regulations. This study found $50(7 \%)$ pilots with a third-class medical in excess of FAA alcohol regulations of 672 third-class medical pilots.

\section{DISCUSSION}

The number of pilot fatalities has decreased over the past 20 years from a high of 1854 to 1353 in the present study, as can be seen in Tables 6-6d. This decrease in accident rates is consistent with other aviation accident reports by the FAA and NTSB (13). Over the 5 -year period of this investigation, there was an estimated average of 573,776 licensed pilots (Table 2); therefore, only $0.2 \%$ of the total pilot population became a fatality requiring toxicology to be performed. Most of the pilots were males ( 1315 or $97 \%$ ), with only 38 or (3\%) female pilots. Licensed female pilots were estimated to be 36,747 during this period, making up $6 \%$ of the total average pilot population of 573,776 . This information suggests that female pilots are less likely to be involved in a fatal aviation accident than their male counterparts.

As shown in Figures 1 and 2, the distribution of medical certificate class and airman certificate type were very similar when the total fatalities group is compared to the group of fatalities found positive for drugs. If we summarized the group that became fatalities during the 2004-2008 period and were found to be positive for a drug based on toxicological submissions, the majority of analyses were conducted on male pilots, mean age of 53, with a third-class medical certificate and designated as private pilots, flying under CFR Part 91. These are generally the same characteristics as for the total group of fatalities.

The percentage of positive drug findings for CI-V drugs has stayed relatively constant over the past 20 years (Table 6) for most drugs. For some drugs such as marijuana, where the instrument methods and Limit of Detection (LOD) remained constant for the past 20 years, the incidence rate remained relatively stable with little or no change (Table 6). PCP has never been detected in fatal pilots tested over the past 20 years by the CAMI laboratory. Some drugs such as fenfluramine were present in early studies but were not found in recent studies. This change reflects the withdrawal of FDA approval for fenfluramine in 1997 and not a sudden shift in drug trends by pilots. Drugs such as zolpidem where not found in earlier studies because the drug was not approved by the FDA until 1992. Synthetic opiate-positives have increased over the past 20 years, but that is not necessarily caused 


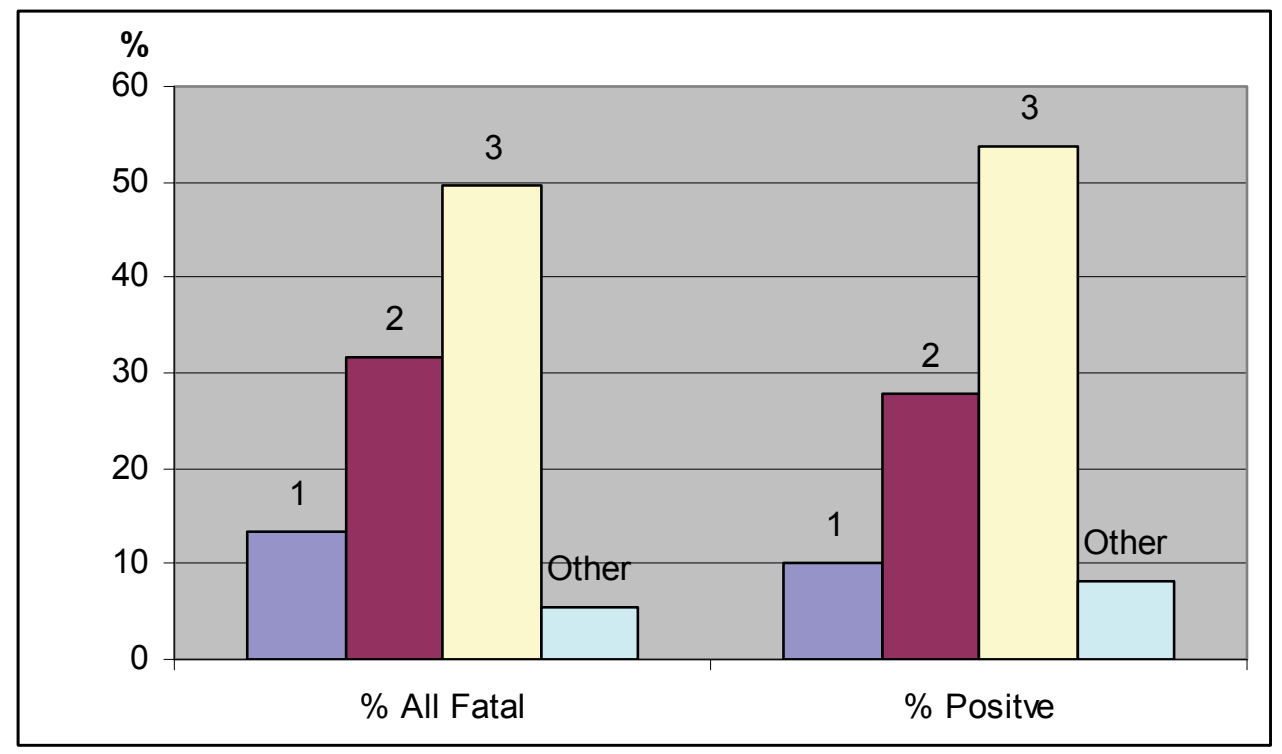

Figure 1. Percentage distribution of medical class for all fatal pilots compared to drug positive fatal pilots.

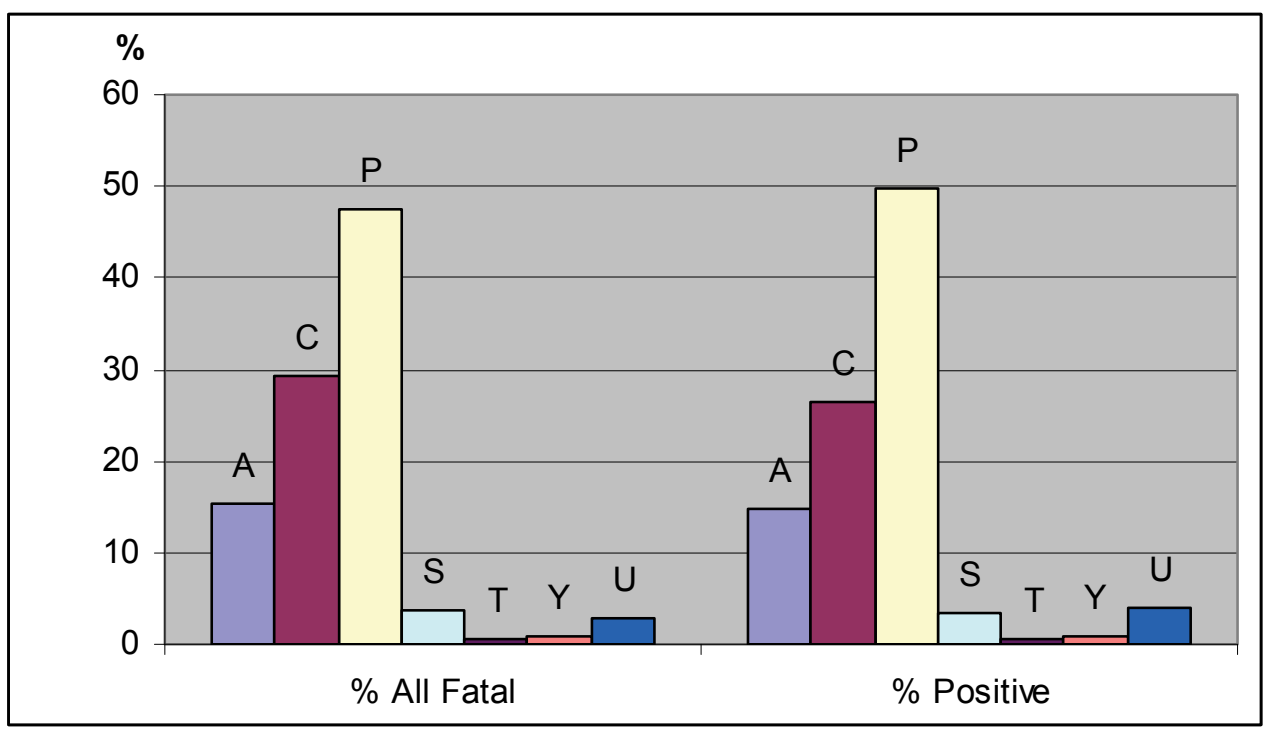

Figure 2. Percentage distribution by pilot license issued for all fatal pilots compared to drug positive fatal pilots. $A=$ Air Transport, $C=$ Commercial, $\mathrm{P}=$ Private, $\mathrm{S}=$ Student $, \mathrm{T}=\mathrm{Sport}, \mathrm{Y}=$ Foreign, $\mathrm{U}=$ Unknown. 
Table 8. Comparison of OTC drug positives for the past 20 years.

\begin{tabular}{|c|c|c|c|c|c|c|c|c|c|}
\hline OTC & $\mathbf{N}=$ & 1845 & $\mathbf{N}=$ & 1683 & $\mathbf{N}=$ & 1587 & $\mathbf{N}=$ & 1353 & \\
\hline Drug & $1989-93$ & $\%$ & 1994-98 & $\%$ & 1999-03 & $\%$ & 2004-08 & $\%$ & Notes \\
\hline Acetaminophen $^{\beta}$ & 92 & 5.0 & 81 & 4.8 & 84 & 5.3 & 50 & 3.7 & FDA $<1989$ \\
\hline Chlorpheniramine/Nor- & 36 & 2.0 & 44 & 2.6 & 31 & 2.0 & 23 & 1.7 & FDA $<1989$ \\
\hline Dextromethorphan/Metabolites & 4 & 0.2 & 26 & 1.5 & 20 & 1.3 & 16 & 1.2 & FDA $<1989$ \\
\hline Doxylamine & 8 & 0.4 & 15 & 0.9 & 19 & 1.2 & 12 & 0.9 & FDA $<1989$ \\
\hline Ephedrine & 1 & 0.1 & 47 & 2.8 & 74 & 4.7 & 29 & 2.1 & FDA $<1989$ \\
\hline Guaiphenesin & 0 & 0.0 & 1 & 0.1 & 0 & 0.0 & 0 & 0.0 & FDA $<1989$ \\
\hline L-Methamphetamine & 0 & 0.0 & 1 & 0.1 & 8 & 0.5 & 1 & 0.1 & FDA $<1989$ \\
\hline Meclizine & 1 & 0.1 & 1 & 0.1 & 0 & 0.0 & 1 & 0.1 & FDA $<1989$ \\
\hline Melatonin & 0 & 0.0 & 1 & 0.1 & 0 & 0.0 & 0 & 0.0 & NA \\
\hline Methylephedrine & 0 & 0.0 & 1 & 0.1 & 0 & 0.0 & 0 & 0.0 & No approved use \\
\hline Naphazoline & 0 & 0.0 & 1 & 0.1 & 0 & 0.0 & 1 & 0.1 & FDA $<1989$ \\
\hline Oxymetazoline & 0 & 0.0 & 1 & 0.1 & 1 & 0.1 & 1 & 0.1 & FDA $<1989$ \\
\hline Phenypropanolamine & 26 & 1.4 & 82 & 4.9 & 76 & 4.8 & 5 & 0.4 & FDA $<1989$ \\
\hline Pseudoephedrine $^{\mu}$ & 47 & 2.5 & 84 & 5.0 & 91 & 5.7 & 56 & 4.1 & FDA $<1989$ \\
\hline Quaiphenesin & 1 & 0.1 & 0 & 0.0 & 0 & 0.0 & 0 & 0.0 & FDA $<1989$ \\
\hline Quinine & 16 & 0.9 & 19 & 1.1 & 37 & 2.3 & 42 & 3.1 & FDA $<1989$ \\
\hline Salicylates $^{\beta}$ & 96 & 5.2 & 114 & 6.8 & 41 & 2.6 & 11 & 0.8 & FDA $<1989$ \\
\hline Simethicone & 0 & 0.0 & 0 & 0.0 & 0 & 0.0 & 1 & 0.1 & FDA 1996 \\
\hline Triprolidine & 0 & 0.0 & 0 & 0.0 & 2 & 0.1 & 2 & 0.1 & FDA $<1989$ \\
\hline
\end{tabular}

$\beta$ - Screening Cutoff Increased in 2002

$\mu$ - Public Law 109-177, 2005 Methamphetamine Precursors ID and Signature Required

by an in increased use of synthetic opiates. A number of new synthetic opiates have been approved by the FDA. Instrumentation and methods have improved over the years, and this may have contributed to the increase in the findings of synthetic opiates in fatally injured pilots. Some of the positives (atropine, lidocaine, narcotic analgesics, etc) found in this study and previous studies may have been administered as a part of emergency medical treatment after the accident.

The first 5-year study (1989-1993) included data from both in-house CAMI laboratory analysis and a contract laboratory that used different methods and cutoffs. This may have contributed to differences found for this early study, compared with more recent studies (1994-2008). Some drugs appear in the most recent study because the CAMI laboratory implemented a base, acid, and neutral drug screen that made it possible to see additional drugs that would not have been possible using only immunoassay and base drug screening methods. Meprobamate was not detected in the earlier studies-even though the drug was available for use during this 20 -year periodmore than likely because it would not have been detected with our immunoassay and base screening method used during those years.

Prescription drugs (29\%) were the most common class of drugs (Table 3) found in this study. Drugs such as citalopram and bupropion were not found in earlier studies because the drugs were not approved for use by the FDA during that time. It is interesting to note that medications such as citalopram, when moved from proprietary to generic, result in an increase in the number of prescriptions for the drug, which subsequently resulted in an increased number of positives found in specimens received for analysis from fatal aviation accidents (Table 7a). This could be caused by a generally significant drop in the overall cost of the drug (14). The increase noted in Table $7 \mathrm{a}$ is consistent with a 2 -fold increase seen in the number of prescriptions sold for citalopram between 2003 and 2004 based on information gathered from Drug Topics, an online magazine that reports the top 200 drugs prescribed each year(15).

Diphenhydramine, a first-generation sedative antihistaminic, with potentially impairing side effects, is currently the most commonly detected medication found in specimens for toxicology analysis from fatal aviation accident pilots. Diphenhydramine positives, over the past 20 years, have steadily increased from $1.7 \%$ to $6.1 \%$ (Table $7 \mathrm{~b}$ and Figure 3). This is an important trend that should be considered when evaluating aviation safety concerns. The Office of Aerospace Medicine is currently evaluating a new equation for pilots to use in determining a safe return to duty time after using impairing medications such as diphenhydramine. The equation developed by forensic toxicology scientists suggests that the simple use of manufacturer's half-life dosing recommendations may be inadequate when considering the potential duration 
Table 7a. Comparison of A-C Prescription drug positives for the past 20 years.

\begin{tabular}{|c|c|c|c|c|c|c|c|c|c|}
\hline \multirow{2}{*}{$\begin{array}{c}\text { Rx } \\
\text { Drug } \\
\end{array}$} & $\mathbf{N}=$ & 1845 & $\mathbf{N}=$ & 1683 & $\mathbf{N}=$ & 1587 & $\mathbf{N}=$ & 1353 & \multirow[b]{2}{*}{ Notes } \\
\hline & $1989-93$ & $\%$ & 1994-98 & $\%$ & 1999-03 & $\%$ & 2004-08 & $\%$ & \\
\hline Alfuzosin & 0 & 0.0 & 0 & 0.0 & 0 & 0.0 & 3 & 0.2 & FDA 2003 \\
\hline Aminophenazone* & 1 & 0.1 & 0 & 0.0 & 0 & 0.0 & 0 & 0.0 & FDA stop 1999 \\
\hline Amitriptyline/Nortriptyline & 2 & 0.1 & 1 & 0.1 & 7 & 0.4 & 2 & 0.1 & FDA $<1989$ \\
\hline Amlodipine & 0 & 0.0 & 0 & 0.0 & 6 & 0.4 & 14 & 1.0 & FDA 1992 \\
\hline Atenolol & 2 & 0.1 & 13 & 0.8 & 14 & 0.9 & 25 & 1.9 & FDA $<1989$ \\
\hline Atropine & 0 & 0.0 & 0 & 0.0 & 24 & 1.5 & 13 & 1.0 & FDA $<1990$ \\
\hline Azacyclonol & 0 & 0.0 & 5 & 0.3 & 5 & 0.3 & 5 & 0.4 & Metabolite \\
\hline Benzocaine & 0 & 0.0 & 0 & 0.0 & 1 & 0.1 & 0 & 0.0 & FDA $<1989$ \\
\hline Bisoprolol & 0 & 0.0 & 0 & 0.0 & 2 & 0.1 & 3 & 0.2 & FDA 1992 \\
\hline Bromopheniramine & 2 & 0.1 & 7 & 0.4 & 2 & 0.1 & 4 & 0.3 & FDA $<1989$ \\
\hline Bupropion & 0 & 0.0 & 0 & 0.0 & 0 & 0.0 & 16 & 1.2 & FDA 1997 \\
\hline Carbamazepine & 3 & 0.2 & 1 & 0.1 & 1 & 0.1 & 0 & 0.0 & FDA $<1989$ \\
\hline Carisoprodol $^{\alpha}$ & 0 & 0.0 & 0 & 0.0 & 0 & 0.0 & 1 & 0.1 & FDA $<1989$ \\
\hline Carvedilol & 0 & 0.0 & 0 & 0.0 & 0 & 0.0 & 5 & 0.4 & FDA 1997, Generic 2007 \\
\hline Cetirizine & 0 & 0.0 & 0 & 0.0 & 3 & 0.2 & 5 & 0.4 & FDA 1996, OTC 2008 \\
\hline Chloroquine & 3 & 0.2 & 0 & 0.0 & 3 & 0.2 & 3 & 0.2 & FDA $<1989$ \\
\hline Cimetidine & 2 & 0.1 & 6 & 0.4 & 9 & 0.6 & 2 & 0.1 & FDA $<1989$ \\
\hline Citalopram/Metabolite(s) & 0 & 0.0 & 0 & 0.0 & 11 & 0.7 & 24 & 1.8 & FDA 1999, Generic 2004 \\
\hline Clonazepam/Metabolite(s) & 0 & 0.0 & 0 & 0.0 & 0 & 0.0 & 1 & 0.1 & FDA $<1989$ \\
\hline Cyclizine & 2 & 0.1 & 0 & 0.0 & 0 & 0.0 & 0 & 0.0 & FDA $<1989$ \\
\hline Cyclobenzoprine & 1 & 0.1 & 0 & 0.0 & 1 & 0.1 & 5 & 0.4 & FDA $<1989$ \\
\hline
\end{tabular}

* - In 1993 changed from TLC screen (base, acid, neutral) to HPLC base screen only.

$\alpha$ - Base, acid, and neutral HPLC and MS screening implemented.

of medication levels that may compromise aviation performance. Diphenhydramine is listed in this study and previous studies as a prescription drug because it is still sold as a prescription as well as an OTC medication, and the CAMI laboratory does not know the origin of the medication found. The CAMI laboratory recognizes that diphenhydramine is readily available in many over-the-counter preparations. It is a first-generation antihistamine and is frequently used to treat allergies. It also has hypnotic and mild anxiolytic effects and is used as a non-prescription sleep aid. Diphenhydramine also may be taken as an antiemetic for motion sickness. Either alone or in combined preparations, it is readily available over the counter.

The CAMI forensic toxicology laboratory identifies new medications shortly after they are approved by the FDA and released to the public for use (Table 7c). For example, varenicline was approved by the FDA in 2006 and was detected in this 2004-2008 study.

Over-the-counter medications are the second most commonly identified medication (13\%) in specimens submitted for toxicology analysis from aviation accidents (Table 8.). Pseudoephedrine is the most commonly identified OTC medication and is found in $4.1 \%$ of the specimens received for analysis from aviation accidents (Table 8). On some occasions a sudden decrease or disappearance of a drug found in early studies will occur because of legislative action taken to restrict access to the medication, as can be seen in pseudoephedrine, where positive pseudoephedrine findings dropped from $5.7 \%$ to $4.1 \%$ after Public Law $109-177$ was passed in 2005 for pseudoephedrine. Both positive identification and Signature were required for pseudoephedrine OTC purchases.

Ethanol (alcohol) was identified in $7 \%$ of the population tested. No pilot flying CFR Part 121 was found to be flying in violation of FAA alcohol regulations. Only one pilot flying CFR Part 135 and one pilot flying CFR Part 137 were found to have ethanol in violation of FAA regulations. Specimens received from these two pilots were putrefied, and the ethanol could have been produced postmortem. Alcohol often forms in specimens received from aviation accidents where the bodies are badly damaged by the crash (16). The pilot flying CFR Part 137 had a 0 urine serotonin metabolite ratio, demonstrating that the ethanol found was not from drinking alcohol. Some of the alcohol-positive cases reported in this study may have been the result of postmortem alcohol formation. 
Table 7b. Comparison of D-P prescription drug positives for the past 20 years.

\begin{tabular}{|c|c|c|c|c|c|c|c|c|c|}
\hline \multirow{2}{*}{$\begin{array}{c}\text { Rx } \\
\text { Drug }\end{array}$} & $\mathbf{N}=$ & 1845 & $\mathbf{N}=$ & 1683 & $\mathbf{N}=$ & 1587 & $\mathbf{N}=$ & 1353 & \multirow[b]{2}{*}{ Notes } \\
\hline & $1989-93$ & $\%$ & $1994-98$ & $\%$ & 1999-03 & $\%$ & 2004-08 & $\%$ & \\
\hline Diltiazem & 2 & 0.1 & 10 & 0.6 & 10 & 0.6 & 9 & 0.7 & FDA $<1989$ \\
\hline Diphenhydramine & 32 & 1.7 & 54 & 3.2 & 83 & 5.2 & 82 & 6.1 & FDA $<1989$, OTC 1990 \\
\hline Doneprezil & 0 & 0.0 & 0 & 0.0 & 0 & 0.0 & 2 & 0.1 & FDA 2005 \\
\hline Doxazosin & 0 & 0.0 & 0 & 0.0 & 1 & 0.1 & 5 & 0.4 & FDA 1990 \\
\hline Doxepine/Nordoxepine & 1 & 0.1 & 0 & 0.0 & 1 & 0.1 & 0 & 0.0 & FDA $<1989$ \\
\hline Etomidate & 0 & 0.0 & 0 & 0.0 & 1 & 0.1 & 4 & 0.3 & FDA $<1989$ \\
\hline Fenoprofen* & 1 & 0.1 & 0 & 0.0 & 0 & 0.0 & 0 & 0.0 & FDA $<1989$ \\
\hline Fluconazole & 0 & 0.0 & 0 & 0.0 & 3 & 0.2 & 0 & 0.0 & FDA 1990, Generic 2004 \\
\hline Fluoxetine/Norfluoxetine & 3 & 0.2 & 18 & 1.1 & 21 & 1.3 & 17 & 1.3 & FDA $<1989$, Generic 2001 \\
\hline Gabapentin & 0 & 0.0 & 0 & 0.0 & 0 & 0.0 & 4 & 0.3 & FDA 1993 \\
\hline Gemfibrozil* $^{*}$ & 5 & 0.3 & 1 & 0.1 & 0 & 0.0 & 0 & 0.0 & FDA $<1989$, Generic 1991 \\
\hline Griseofulvin & 1 & 0.1 & 0 & 0.0 & 0 & 0.0 & 0 & 0.0 & FDA $<1989$ \\
\hline Hydrochlorothiazide $^{\Omega}$ & 0 & 0.0 & 0 & 0.0 & 3 & 0.2 & 1 & 0.1 & FDA $<1989$ \\
\hline Hydroxychloroquine & 0 & 0.0 & 0 & 0.0 & 0 & 0.0 & 1 & 0.1 & FDA $<1989$ \\
\hline Hydroxyzine & 0 & 0.0 & 0 & 0.0 & 1 & 0.1 & 0 & 0.0 & FDA $<1989$ \\
\hline Ibuprofen $^{\alpha}$ & 3 & 0.2 & 9 & 0.5 & 0 & 0.0 & 47 & 3.5 & FDA $<1989$ \\
\hline Imipramine/Desipramine & 2 & 0.1 & 5 & 0.3 & 4 & 0.3 & 2 & 0.1 & FDA $<1989$ \\
\hline Irbesartan & 0 & 0.0 & 0 & 0.0 & 0 & 0.0 & 6 & 0.4 & FDA 1997 \\
\hline Ketamine & 2 & 0.1 & 1 & 0.1 & 0 & 0.0 & 0 & 0.0 & FDA $<1989$ \\
\hline Lamotrigine & 0 & 0.0 & 0 & 0.0 & 0 & 0.0 & 4 & 0.3 & FDA 1995 \\
\hline Lansoprazole & 0 & 0.0 & 0 & 0.0 & 0 & 0.0 & 1 & 0.1 & FDA 1995 \\
\hline Labetalol & 0 & 0.0 & 0 & 0.0 & 1 & 0.1 & 1 & 0.1 & FDA $<1989$ \\
\hline Lidocaine & 31 & 1.7 & 14 & 0.8 & 30 & 1.9 & 12 & 0.9 & FDA $<1989$ \\
\hline Losartan & 0 & 0.0 & 0 & 0.0 & 0 & 0.0 & 4 & 0.3 & FDA 1995 \\
\hline Maprotiline & 1 & 0.1 & 0 & 0.0 & 0 & 0.0 & 0 & 0.0 & FDA $<1989$ \\
\hline Mefloquine & 0 & 0.0 & 0 & 0.0 & 0 & 0.0 & 1 & 0.1 & FDA 2002 \\
\hline Metoclopramide & 2 & 0.1 & 0 & 0.0 & 1 & 0.1 & 1 & 0.1 & FDA $<1989$ \\
\hline Metoprolol & 3 & 0.2 & 5 & 0.3 & 17 & 1.1 & 49 & 3.6 & FDA < 1989, Generic 1994 \\
\hline Minoxidil & 0 & 0.0 & 0 & 0.0 & 0 & 0.0 & 1 & 0.1 & FDA $<1989$ \\
\hline Mirtazapine & 0 & 0.0 & 0 & 0.0 & 2 & 0.1 & 2 & 0.1 & FDA 1996 \\
\hline Moricizine & 0 & 0.0 & 0 & 0.0 & 1 & 0.1 & 0 & 0.0 & FDA 1990, Stop 2007 \\
\hline Nadolol & 0 & 0.0 & 0 & 0.0 & 1 & 0.1 & 0 & 0.0 & FDA $<1989$ \\
\hline Naproxen $^{\alpha}$ & 5 & 0.3 & 7 & 0.4 & 3 & 0.2 & 49 & 3.6 & FDA $<1989$ \\
\hline Nizatidine & 1 & 0.1 & 2 & 0.1 & 1 & 0.1 & 0 & 0.0 & FDA $<1989$ \\
\hline Olanzapine & 0 & 0.0 & 0 & 0.0 & 0 & 0.0 & 3 & 0.2 & FDA 1996 \\
\hline Omeprazole & 0 & 0.0 & 0 & 0.0 & 0 & 0.0 & 13 & 1.0 & FDA 1989 \\
\hline Orphenadrine & 1 & 0.1 & 0 & 0.0 & 0 & 0.0 & 1 & 0.1 & FDA $<1989$ \\
\hline Pantoprazole & 0 & 0.0 & 0 & 0.0 & 1 & 0.1 & 3 & 0.2 & FDA 2000 \\
\hline Paroxetine & 0 & 0.0 & 0 & 0.0 & 16 & 1.0 & 5 & 0.4 & FDA 1992 \\
\hline Phenyltoloxamine & 0 & 0.0 & 0 & 0.0 & 1 & 0.1 & 0 & 0.0 & FDA $<1989$ \\
\hline Phenytoin & 6 & 0.3 & 9 & 0.5 & 0 & 0.0 & 1 & 0.1 & FDA $<1989$ \\
\hline Pioglitazone & 0 & 0.0 & 0 & 0.0 & 0 & 0.0 & 4 & 0.3 & FDA 1999 \\
\hline Procainamide/Acetyl- & 2 & 0.1 & 0 & 0.0 & 2 & 0.1 & 0 & 0.0 & FDA $<1989$ \\
\hline Promethazine & 2 & 0.1 & 3 & 0.2 & 0 & 0.0 & 1 & 0.1 & FDA $<1989$ \\
\hline Propoxyphene/Norp- & 1 & 0.1 & 10 & 0.6 & 12 & 0.8 & 11 & 0.8 & FDA $<1989$ \\
\hline Propranolol & 1 & 0.1 & 3 & 0.2 & 5 & 0.3 & 8 & 0.6 & FDA $<1989$ \\
\hline
\end{tabular}

$\Omega$ - Stopped making Immunoassay kits 


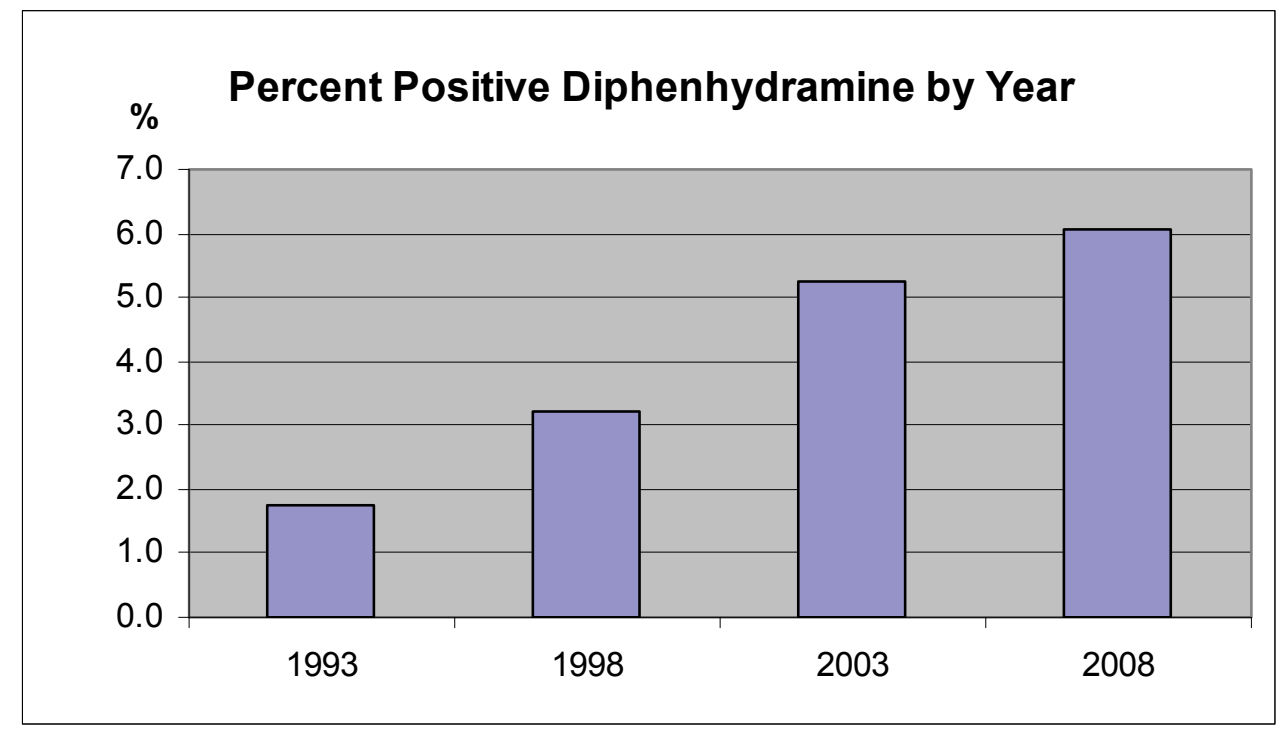

Figure 3. Percent Diphenhydramine by Year.

Table 7c. Comparison of Q-Z Prescription drug positives for the past 20 years.

\begin{tabular}{|c|c|c|c|c|c|c|c|c|c|}
\hline \multirow{2}{*}{$\begin{array}{c}\text { Rx } \\
\text { Drug }\end{array}$} & $\mathbf{N}=$ & 1845 & $\mathbf{N}=$ & 1683 & $\mathbf{N}=$ & 1587 & $\mathbf{N}=$ & 1353 & \multirow[b]{2}{*}{ Notes } \\
\hline & $1989-93$ & $\%$ & $1994-98$ & $\%$ & 1999-03 & $\%$ & 2004-08 & $\%$ & \\
\hline Quetiapine & 0 & 0.0 & 0 & 0.0 & 0 & 0.0 & 1 & 0.1 & FDA 1997 \\
\hline Quinidine & 3 & 0.2 & 0 & 0.0 & 1 & 0.1 & 0 & 0.0 & FDA $<1989$ \\
\hline Ranitidine & 0 & 0.0 & 0 & 0.0 & 17 & 1.1 & 9 & 0.7 & FDA $<1989$ \\
\hline Sertraline & 1 & 0.1 & 5 & 0.3 & 19 & 1.2 & 13 & 1.0 & FDA 1992 \\
\hline Sildenafil & 0 & 0.0 & 1 & 0.1 & 4 & 0.3 & 6 & 0.4 & FDA 1998 \\
\hline Terazosin & 0 & 0.0 & 0 & 0.0 & 0 & 0.0 & 3 & 0.2 & FDA $<1989$ \\
\hline Theophyllline & 1 & 0.1 & 4 & 0.2 & 6 & 0.4 & 0 & 0.0 & FDA $<1989$ \\
\hline Thiopental & 1 & 0.1 & 0 & 0.0 & 0 & 0.0 & 0 & 0.0 & FDA $<1989$ \\
\hline Topiramate & 0 & 0.0 & 0 & 0.0 & 0 & 0.0 & 1 & 0.1 & FDA 1996 \\
\hline Tramadol & 0 & 0.0 & 0 & 0.0 & 12 & 0.8 & 11 & 0.8 & FDA 1995 \\
\hline Trazodone & 0 & 0.0 & 0 & 0.0 & 4 & 0.3 & 5 & 0.4 & FDA $<1989$ \\
\hline Triamterene & 1 & 0.1 & 7 & 0.4 & 8 & 0.5 & 6 & 0.4 & FDA $<1989$ \\
\hline Trimethoprim & 0 & 0.0 & 0 & 0.0 & 5 & 0.3 & 2 & 0.1 & FDA $<1989$ \\
\hline Venlafaxine/Desmethy- & 0 & 0.0 & 0 & 0.0 & 6 & 0.4 & 9 & 0.7 & FDA 1994 \\
\hline Verapamil/Nor- & 5 & 0.3 & 18 & 1.1 & 11 & 0.7 & 4 & 0.3 & FDA $<1989$ \\
\hline Varenicline & 0 & 0.0 & 0 & 0.0 & 0 & 0.0 & 1 & 0.1 & FDA 2006 \\
\hline Warfarin $^{\alpha}$ & 0 & 0.0 & 0 & 0.0 & 0 & 0.0 & 2 & 0.1 & FDA $<1989$ \\
\hline
\end{tabular}


Table 8. Comparison of OTC drug positives for the past 20 years.

\begin{tabular}{|c|c|c|c|c|c|c|c|c|c|}
\hline \multirow{2}{*}{$\begin{array}{l}\text { OTC } \\
\text { Drug }\end{array}$} & $\mathbf{N}=$ & 1845 & $\mathbf{N}=$ & 1683 & $\mathbf{N}=$ & 1587 & $\mathbf{N}=$ & 1353 & \multirow[b]{2}{*}{ Notes } \\
\hline & $1989-93$ & $\%$ & 1994-98 & $\%$ & 1999-03 & $\%$ & 2004-08 & $\%$ & \\
\hline Acetaminophen $^{\beta}$ & 92 & 5.0 & 81 & 4.8 & 84 & 5.3 & 50 & 3.7 & FDA $<1989$ \\
\hline Chlorpheniramine/Nor- & 36 & 2.0 & 44 & 2.6 & 31 & 2.0 & 23 & 1.7 & FDA $<1989$ \\
\hline Dextromethorphan/Metabolites & 4 & 0.2 & 26 & 1.5 & 20 & 1.3 & 16 & 1.2 & FDA $<1989$ \\
\hline Doxylamine & 8 & 0.4 & 15 & 0.9 & 19 & 1.2 & 12 & 0.9 & FDA $<1989$ \\
\hline Ephedrine & 1 & 0.1 & 47 & 2.8 & 74 & 4.7 & 29 & 2.1 & FDA $<1989$ \\
\hline Guaiphenesin & 0 & 0.0 & 1 & 0.1 & 0 & 0.0 & 0 & 0.0 & FDA $<1989$ \\
\hline L-Methamphetamine & 0 & 0.0 & 1 & 0.1 & 8 & 0.5 & 1 & 0.1 & FDA $<1989$ \\
\hline Meclizine & 1 & 0.1 & 1 & 0.1 & 0 & 0.0 & 1 & 0.1 & FDA $<1989$ \\
\hline Melatonin & 0 & 0.0 & 1 & 0.1 & 0 & 0.0 & 0 & 0.0 & NA \\
\hline Methylephedrine & 0 & 0.0 & 1 & 0.1 & 0 & 0.0 & 0 & 0.0 & No approved use \\
\hline Naphazoline & 0 & 0.0 & 1 & 0.1 & 0 & 0.0 & 1 & 0.1 & FDA $<1989$ \\
\hline Oxymetazoline & 0 & 0.0 & 1 & 0.1 & 1 & 0.1 & 1 & 0.1 & FDA $<1989$ \\
\hline Phenypropanolamine & 26 & 1.4 & 82 & 4.9 & 76 & 4.8 & 5 & 0.4 & FDA $<1989$ \\
\hline Pseudoephedrine $^{\mu}$ & 47 & 2.5 & 84 & 5.0 & 91 & 5.7 & 56 & 4.1 & FDA $<1989$ \\
\hline Quaiphenesin & 1 & 0.1 & 0 & 0.0 & 0 & 0.0 & 0 & 0.0 & FDA $<1989$ \\
\hline Quinine & 16 & 0.9 & 19 & 1.1 & 37 & 2.3 & 42 & 3.1 & FDA $<1989$ \\
\hline Salicylates $^{\beta}$ & 96 & 5.2 & 114 & 6.8 & 41 & 2.6 & 11 & 0.8 & FDA $<1989$ \\
\hline Simethicone & 0 & 0.0 & 0 & 0.0 & 0 & 0.0 & 1 & 0.1 & FDA 1996 \\
\hline Triprolidine & 0 & 0.0 & 0 & 0.0 & 2 & 0.1 & 2 & 0.1 & FDA $<1989$ \\
\hline
\end{tabular}

$\beta$ - Screening Cutoff Increased in 2002

$\mu$ - Public Law 109-177, 2005 Methamphetamine Precursors ID and Signature Required

\section{CONCLUSIONS}

For multiple reasons, it is difficult to make detailed direct comparisons between a series of studies in which we or others have previously reported trends. The world and what happens in it changes and can cause changes in toxicological trends over time. Changes occur in a drug's legal status-laboratory instrumentation and methods change, patent rights of drugs, new and different modifications of drugs - just to mention a few. These changes over the years affect our results and thereby influence drug trends that are reported. In addition, differences exist between toxicology laboratories, causing variations in the findings. Inter-laboratory comparisons must be carefully scrutinized as a change in the use of drug trends may only reflect differences between the laboratory methods, instrumentation, and techniques.

Diphenhydramine, an $\mathrm{H}_{1}$ antihistamine with impairing properties, is the most common drug found in pilots who have died in aviation accidents. The FAA has taken steps to warn pilots of the dangers in using this medication that is dispensed as both an $\mathrm{R}_{\mathrm{x}}$ and OTC medication. Because significant aviation performance impairment can be associated with diphenhydramine, the Office of Aerospace Medicine will continue to take steps to help pilots decide when it is safe to resume flying duties after taking such an impairing medication (Figure 3).

We believe that forensic toxicology analysis of pilot fatalities continues to be an important part of the FAA human safety management system. It provides objective scientific information for accident investigation (utilized by both the FAA and National Transportation Safety Board) for assurance of pilot and aeromedical examiner compliance with medical certification requirements, feedback to aviation drug abatement programs and their effectiveness, and for medico/legal adjudication of aviation-related cases. 


\section{REFERENCES}

1. Canfield D, Flemig J, Hordinsky J, Berky M. Drugs and alcohol found in aviation accidents between 1989 and 1993. FAA Office of Aviation Medicine Report No. AM-95/28. Washington, DC; 1995.

2. Canfield DV, Hordinsky J, Millett DP, Endecott B, Smith D. Prevalence of drugs and alcohol in fatal civil aviation accidents between 1994 and 1998. Aviation, Space, and Environmental Medicine. 2001 Feb;72(2):120-4.

3. Chaturvedi AK, Craft KJ, Canfield DV, Whinnery JE. Toxicological findings from 1587 civil aviation accident pilot fatalities, 1999-2003. Aviation, Space, and Environmental Medicine. 2005 Dec;76(12):11454.

4. Kuhlman JJ, Jr., Levine B, Smith ML, Hordinsky JR. Toxicological findings in Federal Aviation Administration general aviation accidents. Journal of Forensic Sciences. 1991 Jul;36(4):1121-8.

5. McBay AJ. Drugs and transportation safety. Journal of Forensic Sciences. 1990 May;35(3):523-9.

6. Ruehle CJ. Toxicologic studies on USAF aircraft accident casualties, 1973-1984. Aviation, Space, and Environmental Medicine. 1989 Oct;60(10 Pt 2):B86-8.

7. Blackmore DJ. Aircraft accident toxicology: U.K. experience 1967-1972. Aerospace Medicine. 1974 Aug;45(8):987-94.

8. Davis GL. Postmortem alcohol analyses of general aviation pilot fatalities, Armed Forces Institute of Pathology, 1962-1967. Aerospace Medicine. 1973 Jan;44(1):80-3.
9. Smith PW, Lacefield DJ, Crane CR. Toxicological findings in aircraft accident investigation. Aerospace Medicine. 1970 Jul;41(7):760-2.

10. Drug Abuse Warning Network. National estimates of drug-related emergency department visits. U.S. DHHS, Substance Abuse and Mental Health Services Administration. Rockville, MD; 2007.

11. Chaturvedi AK, Smith DR, Soper JW, Canfield DV, Whinnery JE. Characteristics and toxicological processing of postmortem pilot specimens from fatal civil aviation accidents. Aviation, Space, and Environmental Medicine. 2003 Mar;74(3):252-9.

12. U.S. civil airmen statistics. May 14, 2009 [accessed 9/8/11]; Availablefrom:www.faa.gov/data_research/ aviation_data_statistics/civil_airmen_ statistics/2008.

13. NTSB. Accidents, fatalities, and rates, 1990 through 2009 U.S. general aviation. 2010.

14. Scott A. More people abandoning prescriptions. Drug Topics. [Online Article] 2009 [cited 12/14/2010]; Available from: www.modern medicine.com/modernmedicine/article/article Detail.jsp?id=593703.

15. Marketos M. The top 200 brand drugs in 2003 (by units). Drug Topics. [cited 9/8/11]. Available from: http://drugtopics.modernmedicine.com/ drugtopics/article/articleDetail.jsp?id=109800. 2004.

16. Canfield DV, Kupiec T, Huffine E. Postmortem alcohol production in fatal aircraft accidents. Journal of Forensic Sciences. 1993 Jul;38(4):914-7. 
